\section{University of New Hampshire}

Carsey School of Public Policy

\section{CARSEY RESEARCH}

National Issue Brief \#149

Summer 2020

\title{
'Outlaw Operators'
}

\section{Prevention Failures and the Resurgence of Black Lung in Central Appalachia}

\section{Aysha A. Bodenhamer}

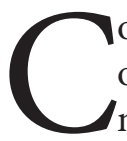
oal workers' pneumoconiosis, a preventable occupational and environmental disease commonly referred to as black lung, was thought to be a moot issue after the enactment in 1969 of the Coal Mine Health and Safety Act, which created sweeping health and safety reforms and was followed by a significant decline in black lung cases. However, the disease became resurgent in the United States in the early 2000s, ${ }^{1}$ and it is back in central Appalachia at unprecedented levels. Recently, 20.6 percent of long-tenure miners (25-plus years) who were tested in Kentucky, Virginia, and West Virginia tested positive for black lung. ${ }^{2}$

This brief, based on interviews with miners, clinic workers, black lung attorneys, government employees, and lay advocates as well as a case-study analysis of two black lung clinics in southwest Virginia, describes how prevention failures in the coal mining industry have resulted in the resurgence of black lung.

\section{The Horror of Black Lung}

Caused by the chronic inhalation of coal and silica dust, black lung is progressive, incurable, life-altering, and fatal. ${ }^{3}$ One miner interviewed for this study described his experience as a "smothering sensation":

It's almost like a sensation that you're drowning on dry land. Especially when it progresses. You really never can catch enough breath, and over time it gets worse and worse, and so you're sort of gasping for air. Even in a seated position - not moving, not exercising-you just can't get enough air into your lungs. You can't get enough oxygen into your blood. And then it just goes downhill until your body physically just can no longer survive with that little amount of oxygen and you die. ${ }^{4}$

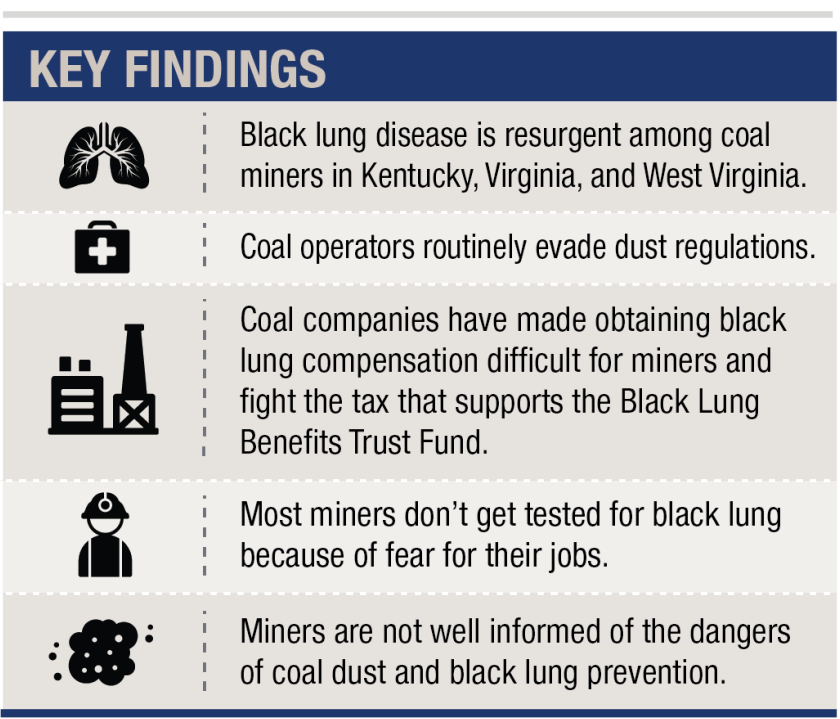

Black lung slowly corrodes the quality of life of miners and their families until it eventually leads to death: "I'm aggravated that I can't do things. It's just there all the time."

\section{Failed Prevention Efforts}

What is most troubling about black lung is that it is preventable. ${ }^{5}$ Many interviewees, particularly government officials within the National Institute for Occupational Safety and Health (NIOSH) and the Mine Safety and Health Administration (MSHA) claim that if dust protocols were followed, black lung would not exist. This interviewee, a pulmonologist, states:

I always say, it's not rocket science; you get black lung disease from breathing too much coal dust. It's very simple. We know what causes it, we know how to prevent it, we know that the measures that are in place in law can prevent the majority of [black lung] disease that's out there. And the frustration for me is the fact that that is not upheld. ${ }^{6}$ 


\section{Noncompliance With Dust Regulations and Falsified Dust Sampling}

Noncompliance with dust regulations is a notable concern among Appalachian miners. Regulators, other government employees, and miners who were interviewed note that negligent dust practices and fraudulent dust sampling have become commonplace in many Appalachian mines, yet coal operators report "compliant" numbers. As one regulator notes:

Cheating on the dust sampling, that still goes on all the time.... The old system....is basically this dust pump that just measures how much dust is collected into it....There's nothing in the apparatus that can say where it's been during this time. And what would typically happen, and a million guys tell me this sort of thing, you would wrap it [dust monitor] in rags. You would put it in a dinner bucket. You would go hang it in the fresh air intake, where nothing but clean air is blowing over it the whole time. ${ }^{7}$

Hiding evidence from inspectors and falsifying dust samples has become so routinized in the mines, interviewees say, that miners are instructed to change practices when inspectors are present: "Their [the coal operators] main reason is to make money and run coal. If inspectors come, more is done to cover the dust." Many miners report that ventilation curtains were only hung when inspectors were present. Since underground mines are typically inspected four times a year, this assertion implies that mines are likely operating incorrectly 361 days a year. Most research participants argue that many coal operators do not follow dust regulations because it costs too much money, and that this "outlaw operator" phenomenon is unique to central Appalachia: "You just have more outlaw operators here. You just do. More scofflaw." ${ }^{8}$ But it is the experience of interviewees that Appalachian coal companies continue to deny culpability and routinely externalize the cost of black lung:

I was shocked when this person in the coal industry told me, 'It's just not relevant to us because we don't pay for it'...in other words, there's not a human value there at all. There's nothing - that there are people who are dying and are having a miserable life gasping for breath, and that's not a relevant concern. ${ }^{9}$

\section{Poor Training and Understanding of Chronic Dust Exposure}

Despite evidence that black lung is preventable, central Appalachia is in the midst of the largest spike in prevalence in over 30 years. Many miners believe that black lung is inevitable: "There ain't no way of preventing it. They make respirators. Some do and some don't [wear them]. I don't see any way of avoiding black lung." The twin perceptions that black lung is not preventable and that a miner is personally to blame for not using a respirator are common among coal workers. However, respirators have been shown to be an unreliable line of defense, ${ }^{10}$ and quality problems plague their users: in $2018,3 \mathrm{M}$ paid $\$ 67.5$ million to Kentucky miners who used faulty respirators in coal mining operations. ${ }^{11}$ Miners continue to believe that respirators are approved mechanisms of defense, but dust prevention requires mechanical controls such as water sprays, scrubbers, and ventilation systems. ${ }^{12}$ These misconceptions point to deficient miner safety and health training.

\section{Black Lung Screening}

Mines are required to arrange opportunities for annual black lung screenings, free of charge, but few miners take advantage of them. According to a government official, "They get a free test every year from the Department of Labor.... They can do it every year for the rest of their lives." Yet interviews suggest that many miners remain fearful of losing their jobs if they get tested for black lung, even though NIOSH assures that screening is confidential. One research participant said that miners "are afraid...because if the coal company finds out that they are going to a black lung clinic, or that they are having chest x-rays done, they're going to fire them and get somebody else in to work." In this sense, proactive miners who wish to be tested for black lung are equivalent to whistleblowers in the company's eyes, thus creating a vulnerable situation for themselves and their communities. Regions with stagnant economies are even more defenseless. Some researchers argue that this culture of fear resonates among miners due to precarious coal employment in Appalachia. ${ }^{13}$ 
Figure 1 uses data from NIOSH's Coal Workers' Health Surveillance Program (CWHSP) to show the continued concentration of black lung in central Appalachia (the region situated in Kentucky, Virginia, and West Virginia) compared to the rest of the United States. Although the CWHSP is immensely helpful for tracking black lung prevalence, its estimates capture only active and voluntary miners who have been tested; many retired and untested active miners are not represented in its data. Annual mandatory testing of all miners would limit the unfavorable bias toward proactive miners and allow the collection of accurate black lung data.

MSHA has sanctioned some health and safety improvements in recent years. For instance, MSHA recently decreased the respirable dust limit from $2 \mathrm{mg} / \mathrm{m}^{3}$ to $1.5 \mathrm{mg} /$ $\mathrm{m}^{3}$ after the previous limit was found to be ineffective. MSHA also implemented the use of continuous personal dust monitors to cut down on dust fraud and improve real-time reporting. ${ }^{14}$ The outcomes of these changes are unknown at this time; indeed, the lag effect of black lung could leave us uninformed for years to come. While these changes are important, they are inadequate without industry buy-in and government enforcement.

\section{FIGURE 1. PERCENTAGE OF ACTIVE, UNDERGROUND, LONG-TENURE (25-PLUS YEARS) COAL MINERS WITH BLACK LUNG IN KENTUCKY, VIRGINIA, AND WEST VIRGINIA COMPARED TO THE REST OF THE UNITED STATES, 1974-2017}

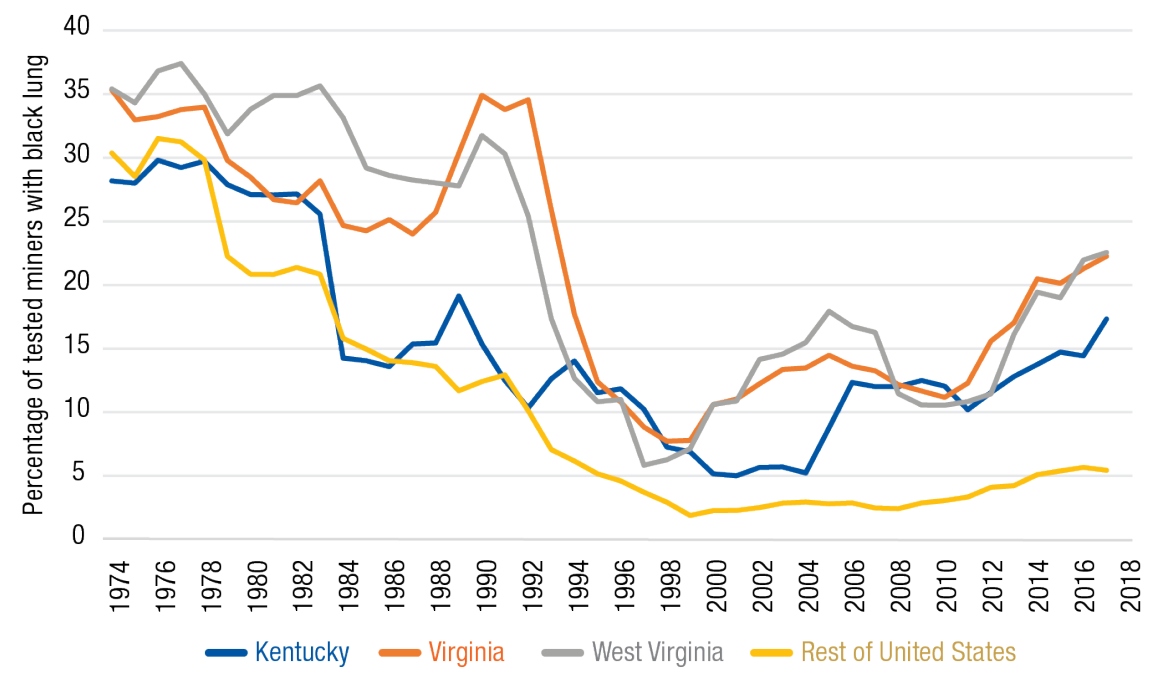

Note: Data include only active miners who voluntarily participated in black lung screening.

Source: NIOSH Coal Workers Health Surveillance Program Data Query System, 2020 (https://webappa.cdc.gov/ords/cwhsp-database.html)

\section{Black Lung \\ Compensation Claims}

While the deficiencies of black lung prevention are many, black lung compensation is equally problematic. In West Virginia at least, miners are developing black lung at unprecedented rates, even though fewer are tested (see Figure 2). Given the progressive nature of black lung even after dust exposure stops, this upward trend is alarming. And though coal employment is at a historic low, production trends have recently increased after a long

\section{FIGURE 2. TOTAL MINERS TESTED AND PERCENTAGE OF MINERS WITH} BLACK LUNG IN WEST VIRGINIA, 1970-2014

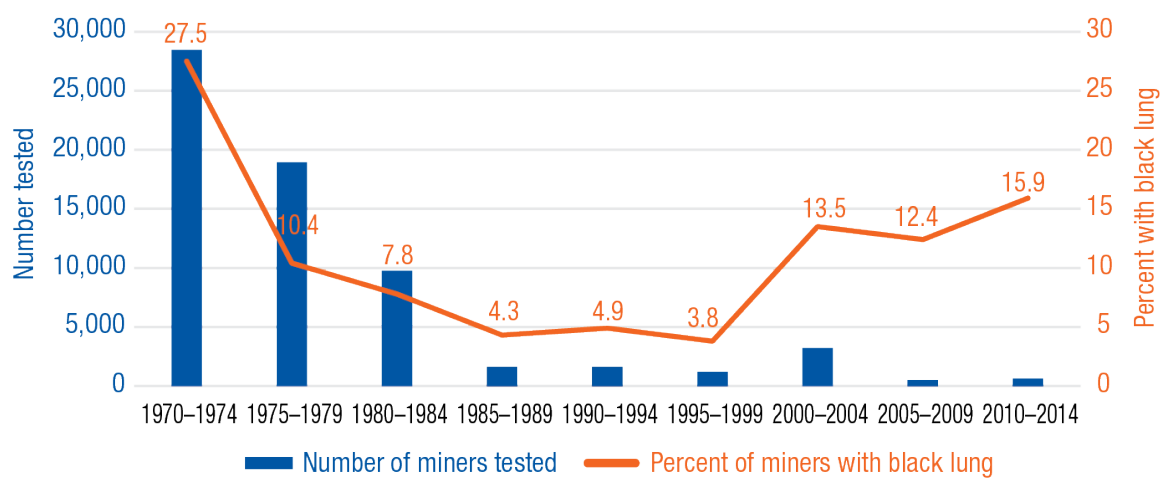

Source: NIOSH Coal Workers Health Surveillance Program Data Query System, 2020 (https://webappa.cdc.gov/ords/cwhsp-database.html) 
downward spiral (see Figure 3). This trend could imply that miners are being overexposed to coal dust as fewer employees work longer hours to make up for a reduced workforce. Moreover, many coal companies have filed for bankruptcy, putting miners' health care, pensions, and black lung benefits at risk.

Black lung benefits consist of a monthly payment of $\$ 669.30$ and a medical card for single filers. Only 18.02 percent of filed black lung claims were awarded in $2017,{ }^{15}$ and the average time it took for miners in this study to acquire their benefits was six years, with a range from one year to two decades. Yet despite the low disbursement rates and rising prevalence, the coal industry continues to demand lower tax rates. Even during the COVID-19 pandemic, the National Mining Association has promoted a 50 percent cut to the $\$ 1.10 /$ ton excise tax for underground coal and $\$ 0.55$ tax for surface coal that are used to fund the Black Lung Benefits Trust Fund. ${ }^{16}$ The fund has nearly always operated at a deficit, and decreasing the coal excise tax would ultimately shift the financial burden of black lung benefits from coal operators to taxpayers.

Black lung is not only a public health disaster, ${ }^{17}$ it is also a social justice issue. Receiving compensation for black lung is rooted in an adversarial process: miners must prove their work history and total disability from black lung before they have a "legitimate" case. These legal battles between miners and goliath coal company legal teams are often insurmountable for miners, given their limited resources and time, and even after being awarded benefits many miners fear losing them due to the precarious nature of the industry.

FIGURE 3. WEST VIRGINIA COAL PRODUCTION AND EMPLOYMENT, 1900-2018

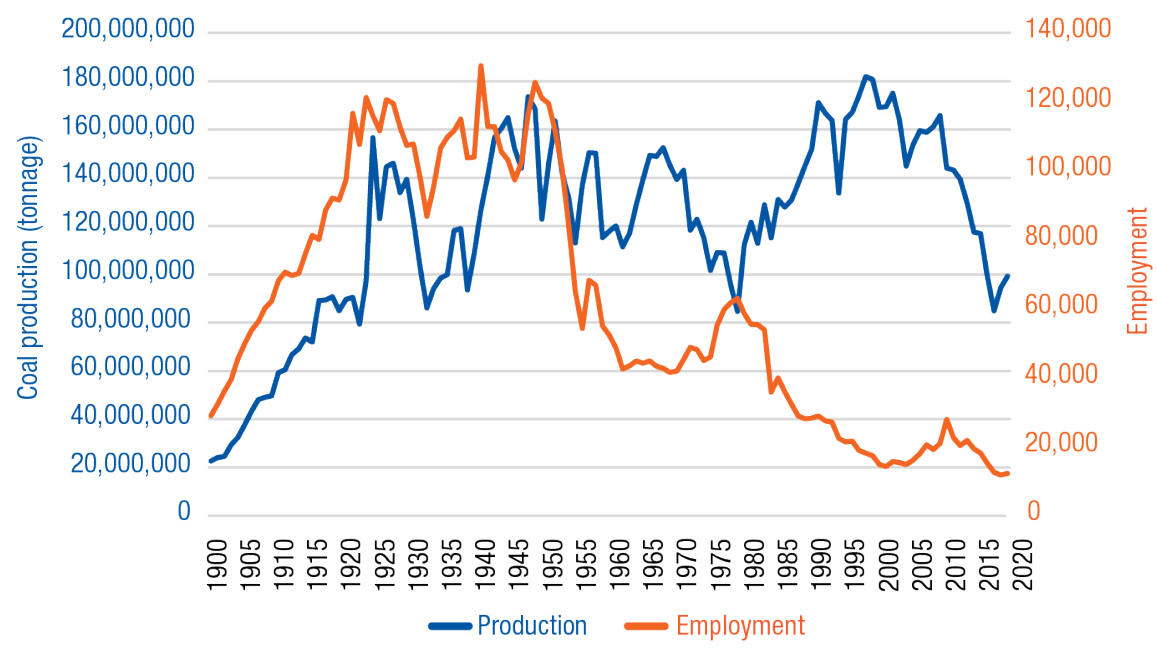

Source: West Virginia Coal Association, "Coal Facts 2019," 2019

(https://www.wvcoal.com/resources/coal-facts/5176-coal-facts-2019)

Issues such as skirting regulations, falsifying records, and putting workers at risk are not isolated events or unique to the coal mining industry. Many workers across the industrial spectrum experience similar precarious work environments in which profit is prioritized over human health and safety. Shortcuts to safety and health create only short-term gains, while the accumulated longterm cost and risk are much greater. We must provide safe work environments for all employees, as intended by the Department of Labor.

\section{Opportunities for Policy and Practice}

- Industry buy-in and government enforcement of mine safety regulations are essential. The coal industry must follow dust protocols and implement appropriate mechanical dust controls. Coal companies must be held responsible by government agencies for failing to prevent black lung.

- Coal companies should receive briefings on NIOSH data trends, up-to-date research findings, and best practices in the workplace, and participate in the National Coalition of Black Lung and Respiratory Disease Clinics annual conference.

- Miners should receive updated and improved annual MSHA miner safety training and a confidential, secure means of reporting safety violations.

- More frequent MSHA checkins and inspections should be instituted to enhance compliance with health and safety standards.

- Mandatory annual black lung screenings should be instituted in order to eliminate the stigma felt by proactive coal workers.

- The adversarial nature of black lung compensation claims should be reformed, and a sliding scale of benefits should be created for miners with a black lung diagnosis.

- The coal excise tax should be increased by $\$ 0.25 /$ ton to eliminate the Black Lung Benefits Trust Fund debt and secure the fund for future claimants. ${ }^{18}$ 


\section{Data and Methods}

This research is based on four years of triangulated qualitative and quantitative data. Primary data were accumulated through in-depth interviews starting in 2015 with 25 key informants including miners, black lung clinic workers, black lung attorneys, government employees, and lay advocates. A second wave of data collection commenced in 2019 with a case-study analysis of two black lung clinics in southwest Virginia. Twenty-four additional interviews with miners and clinic workers were collected during this time, for a total of 59 interviews. Quantitative data for coal production and employment are reported by the West Virginia Coal Association in its annual Coal Facts publication. ${ }^{19}$ Prevalence data for central Appalachia are collected by the National Institute of Occupational Safety and Health through the Coal Workers' Health Surveillance Program. ${ }^{20}$ These data are aggregated at the county level and reported in five-year intervals.

Additional data were gathered through participant observation, document analysis, and news articles. Participant observation took place in 2015, 2016, and 2018 at the national and regional black lung conferences supported by the National Coalition of Black Lung and Respiratory Disease Clinics. To triangulate and extend the analysis, I also incorporated document analysis from government agencies including NIOSH, the MSHA, and the Division of Coal Mine Workers' Compensation; the United Mine Workers of America; and news articles.

\section{Endnotes}

1. V.C. dos S. Antao, E.L. Petsonk, L.Z. Sokolow, A.L. Wolfe, G.A. Pinheiro, J.M. Hale, and M.D. Attfield, "Rapidly Progressive Coal Workers' Pneumoconiosis in the United States: Geographic Clustering and Other Factors," Occupational and Environmental Medicine 62, no. 10 (2005): 670-74.

2. David J. Blackley, Cara N. Halldin, and A. Scott Laney, "Continued Increase in Prevalence of Coal Workers' Pneumoconiosis in the United States, 1970-2017," American Journal of Public Health 108, no. 9 (2018): 1220-22.

3. Jarek M. Mazurek et al., "Coal Workers' Pneumoconiosis: Attributable Years of Potential Life Lost to Life Expectancy and Potential Life Lost Before Age 65 Years-United States, 1999-2016," Morbidity and Mortality Weekly Report 67, no. 30 (2018): 819.

4. Personal interview, July 15, 2016.

5. Kirsten S. Almberg, Cara N. Halldin, David J. Blackley, A. Scott Laney, Eileen Storey, Cecile S. Rose, Leonard H.T. Go, and Robert A. Cohen, "Progressive Massive Fibrosis Resurgence Identified in U.S. Coal Miners Filing for Black Lung Benefits, 1970-2016," Annals of the American Thoracic Society 15, no. 12 (2018): 1420-26.

6 . Personal phone interview, January 29, 2016.

7. Personal interview, June 10, 2016.

8. Personal interview, July 15, 2016.

9. Personal interview, December 8, 2015.

10. Howard Berkes, "Black Lung:

Why Respirators Are Not a

Solution," National Public Radio, July 9, 2012, https://www.npr. org/2012/07/09/156375910/black-lungwhy-respirators-are-not-a-solution.

11. Bill Estep, "Kentucky Jury Awards

$\$ 67.5$ Million to Miners Who Used

Defective Dust Masks," Lexington

Herald Leader, April 25, 2018, https://

www.kentucky.com/news/state/

article209783724.html.
12. Jay F. Colinet, James P. Rider, Jeffrey M. Listak, John A. Organiscak, and Anita L. Wolfe, "Best Practices for Dust Control in Coal Mining" (Washington, DC: Department of Health and Human Services, 2010), https://www.cdc. gov/niosh/mining/UserFiles/works/ pdfs/2010-110.pdf.

13. Aysha Bodenhamer and Thomas E. Shriver, "Environmental Health Advocacy and Industry Obstruction: The Case of Black Lung Disease," Rural Sociology (2020): 1-23.

14. Department of Labor, Mine Safety and Health Administration, 79 Fed. Reg. 84 (May 1, 2014).

15. Division of Coal Mine Workers' Compensation, "Black Lung Program Statistics," 2017, https://www.dol. gov/owcp/dcmwc/statistics/bls2017/ PartCBlackLungClaimAdjudications.htm. 16. Will Englund, "As Covid-19 Hits, Coal Companies Aim to Cut the Tax They Pay to Support Black-Lung Miners," Washington Post, April 8, 2020, https://www.washingtonpost.com/ business/2020/04/08/coal-black-lungcoronavirus/.

17. Alan Derickson, Black Lung: Anatomy of a Public Health Disaster (Ithaca, NY: Cornell University Press, 1998).

18. Robert Miller, "Overview of the GAO’s Report on BLBP," presentation to the West Virginia Black Lung Conference, Pipestem WV, June 6-9, 2018.

19. West Virginia Coal Association, "Coal Facts 2019," 2019, https://www. wvcoal.com/resources/coal-facts/5176coal-facts-2019.

20. Coal Workers' Health Surveillance Program, National Institute of Occupational Safety and Health, 2020, https://www.cdc.gov/niosh/topics/ cwhsp/default.html. 


\section{About the Author}

Aysha Bodenhamer, $\mathrm{PhD}$, is an assistant professor of Sociology in the College of Humanities and Behavioral Sciences at Radford University. Her research examines the intersection of energy, environment, and human populations. Her recent research focuses on extractive industries and contested environmental illnesses; particularly, the resurgence of black lung in central Appalachia. Aysha holds a PhD in Sociology from North Carolina State University.

\section{A cknowledgments}

The author would like to thank Shannon Monnat, Michael Ettlinger, Jess Carson, Laurel Lloyd, and Patrick Watson for helpful suggestions on earlier drafts. The author would also like to thank NIOSH for their data support. Funding for this project was provided by the Rural Sociological Society and the College of Humanities and Behavioral Sciences at Radford University. The views expressed in this brief represent those of the author and should not be attributed to these organizations.

\section{University of New Hampshire} Carsey School of Public Policy

The Carsey School of Public Policy at the University of New Hampshire is nationally recognized for its research, policy education, and engagement. The school takes on the pressing issues of the twenty-first century, striving for innovative, responsive, and equitable solutions.

Huddleston Hall • 73 Main Street • Durham, NH 03824

(603) 862-2821

TTY Users: DIAL 7-1-1 OR 1-800-735-2964 (RELAY N.H.)

carsey.unh.edu 